\title{
Reduced Mobility But Unaffected Startle Response in Female Rats Exposed to Prenatal Dexamethasone: Different Sides to a Phenotype
}

\author{
S.L. Kjaer ${ }^{a}$ b $\quad$ G. Wegener ${ }^{a} \quad$ R. Rosenberg ${ }^{a} \quad$ K.S. Hougaard ${ }^{b}$
}

${ }^{a}$ Centre for Psychiatric Research, Aarhus University Hospital Risskov, Risskov, and ${ }^{b}$ National Research Centre for the

Working Environment, Copenhagen, Denmark

\section{Key Words}

Anxiety - Mental illness - Forced swim test - Behavior •

Environmental impact $\cdot$ Animal model $\cdot$ Dexamethasone $\cdot$

Pregnancy $\cdot$ Stress

\begin{abstract}
An adverse fetal environment is strongly associated with behavioral and emotional development in later life, and environmental interactions with the genome are essential in the development of pathophysiology. This implicates that a genetic vulnerability or other predisposition may interact with the environment and stressful life events to trigger mental disease. The startle reflex is highly sensitive to fear and anxiety in humans and animals. Elevated startle magnitude has been proposed as a marker for neurodevelopmental disorders. We have recently established an animal model for possible development of anxiety, where female rats are exposed to two stressful life events, during prenatal life and as adolescents, respectively. A blood sampling procedure 3 months prior to startle testing has previously been found to increase basal startle, but only in prenatally stressed rats. As the experimental procedure of acoustic startle response (ASR) measurement resembles the aversive blood sampling procedure, this suggests that effects on ASR may be caused by aversive contextual similarities between blood sampling un-
\end{abstract}

der restraint and the ASR test. In the present study, postnatal blood sampling was replaced by another dissimilar stressful event. Animals exposed to a high prenatal glucocorticoid level (i.e. $150 \mu \mathrm{g}$ dexamethasone $/ \mathrm{kg}$ ) were statistically significantly more immobile in the forced swim test (FST) than animals exposed to a lower level of dexamethasone $(50 \mu \mathrm{g} /$ $\mathrm{kg}$ ) and control animals. Exposure to a novel contextual stressor at 3 months of age (FST) was unassociated with changes in basal startle. These data suggest, since the high prenatal dexamethasone group showed increased immobility in the FST but coped equally well with controls in the ASR, that the outcome of environmental influences is determined by the individual circumstances as different situations require different coping abilities in the same individual.

Copyright $\odot 2010$ S. Karger AG, Basel

\section{Introduction}

A large number of human and animal studies show a strong association between an adverse fetal environment and behavioral and emotional development in later life [Abe et al., 2007; Maccari et al., 2003; Nagano et al., 2008; O'Connor et al., 2002; Tazumi et al., 2005; Van den Bergh et al., 2005]. Data from animal studies provide evidence that prenatal exposure to glucocorticoids restricts fetal

\section{KARGER}

Fax +4161306 1234 E-Mail karger@karger.ch www.karger.com (c) 2010 S. Karger AG, Basel

0378-5866/10/0323-0208\$26.00/0

Accessible online at:

www.karger.com/dne
Karin Sørig Hougaard

National Research Centre for the Working Environment

Lersø Parkallé 105

DK-2100 Copenhagen (Denmark)

Tel. +45 3916 5217, Fax +45 3916 5201, E-Mail ksh@nrcwe.dk 
growth and suggest a role in programming the individual to adult disease [Hossain et al., 2008; Nagano et al., 2008; Newnham and Moss, 2001; Seckl, 2004; Seckl and Meaney, 2004; Weaver, 2009].

The acoustic startle response (ASR) is a characteristic sequential contraction of the skeletal musculature evoked by a sudden and intense acoustic stimulus [Koch, 1999]. In animals and humans, stimuli that induce fear and anxiety or administration of anxiogenic agents increase the startle response [Grillon, 2008]. In humans, elevated startle magnitude has been proposed as a marker for anxiety disorders, including anxiety and post-traumatic stress disorder, and possibly for major depressive disorder [Bakker et al., 2009; Grillon, 2002; Grillon et al., 2005]. Studies on anxiety and depressive disorders are important as these diseases constitute a substantial proportion of the global burden of disease [World Health Organization, 2008]. Also, an increase in studies using female animals is warranted in this research field as women have a higher burden of anxiety and depression than men [World Health Organization, 2008].

We have previously observed exaggerated startle in prenatally stressed or prenatally dexamethasone (DEX)exposed female rats, but only in animals undergoing blood sampling under restraint prior to ASR testing [Hougaard et al., 2005a, b]. ASR testing involves confinement to a test tube. This resembles the experimental circumstances of blood sampling under restraint. In classic Pavlovian fear conditioning, a conditional stimulus is paired with an aversive unconditional stimulus in a novel context. After even a single pairing, animals will exhibit fear to the conditional stimulus, but also to the conditioning chamber and circumstances surrounding the conditioning episode [Anagnostaras et al., 2000]. Tazumi et al. [2005] observed increased baseline startle in prenatally stressed rats 1 week after exposure to light-potentiated startle, suggestive of contextual conditioning in these animals between the apparatus and the bright light. Therefore, it can be hypothesized that just one previous exposure to bright light during startle testing [Tazumi et al., 2005] or blood sampling in a bright room while being held in a restrainer in our lab [Hougaard et al., 2005a, b] could act as the unconditional stimulus/conditional stimulus/context pairing which induced the exaggerated startle in the subsequent startle test. This hypothesis is supported by studies using repeated exposure to a restrainer as a basis in post-traumatic stress disorder models [Harvey et al., 2003, 2004; Oosthuizen et al., 2005].

In the forced swim test (FST), the animals are tested for immobility, which is interpreted as either failure of persis- tence in escape-directed behavior (i.e. behavioral despair) or development of passive behavior that disengages the animal from active forms of coping with stressful stimuli [Lucki, 1997]. In the present study, the FST was used both as a postnatal stressor and as a test in itself. This allowed us to investigate new aspects of our animal model, i.e. the association between FST and ASR and coping behavior.

Stressful experiences during gestation and early life have been hypothesized to enhance susceptibility for mental illness [Cottrell and Seckl, 2009; Fumagalli et al., 2007; Maynard et al., 2001] but a few studies in both humans and animals have shown an association between mild prenatal stress and protective or adaptive behavioral effects: mild to moderate levels of prenatal psychological stress were positively associated with mental development and advanced motor development in 2-year-old children [DiPietro et al., 2006], and prenatally stressed or DEX-exposed rats showed enhanced learning performance [Fujioka et al., 2001; Hougaard et al., 2005a] or lower stress-induced plasma corticosterone levels compared with controls [Van den Hove et al., 2005]. It has yet to be resolved why some individuals thrive under stressful conditions while others strive to survive. But it can be hypothesized that a system which during development has been exposed to mild levels of stress might become adapted to handling a stressor postnatally, whereas a naïve system would be less successful.

Therefore, in the present work, we hypothesized that a high level of prenatal DEX would inhibit constructive coping whereas a lower dose of prenatal DEX might facilitate coping with postnatal stressful life experiences. The aims of this study were to examine (i) if prior exposure to a postnatal stressor, lacking contextual similarities with the ASR test, would induce changes in ASR in prenatally DEX-exposed animals and (ii) if prenatal exposure to a high versus a lower dose of DEX would result in different behavioral phenotypes.

\section{Materials and Methods}

Chemicals

DEX was obtained from Sigma-Aldrich, Denmark. The DEX used for animal experimentation was dissolved in $4 \%$ ethanol/ isotonic saline.

\section{Animals}

Sixty time-mated young adult rats (Wistars, HanTaC:WH, SPF) arrived at gestational day (GD) 4. The rats were randomly distributed pairwise to white plastic cages (Eurostandard III, $27 \times 43 \times 18 \mathrm{~cm}$, Scanbur, DK) with pine-bedding (Lignocel S8, Brogaarden ${ }^{\circledR}$, Denmark). The cages also contained nesting mate- 
Table 1. Schematic overview of group exposures

\begin{tabular}{llll}
\hline Group & $\begin{array}{l}\text { Prenatal exposure } \\
\text { to DEX GD 14-21 }\end{array}$ & $\begin{array}{l}\text { FST } \\
3 \text { months }\end{array}$ & $\begin{array}{l}\text { Acoustic startle } \\
\text { test } 6 \text { months }\end{array}$ \\
\hline CON & & $\times$ & $\times$ \\
CONfst & $\times$ & & $\times$ \\
DEXlow & $\times$ & $\times$ & $\times$ \\
DEXlowfst & $\times$ & & $\times$ \\
DEXhigh & $\times$ & $\times$ & $\times$ \\
DEXhighfst & $\times$ & & $\times$ \\
\hline
\end{tabular}

CON $=$ Control; DEXlow $=$ DEX $50 \mu \mathrm{g} / \mathrm{kg} /$ day; DEXhigh $=$ DEX $150 \mu \mathrm{g} / \mathrm{kg} /$ day; FST = forced swim test.

rial (Enviro-Dri, Brogaarden ${ }^{\circledR}$, Denmark), and environmental conditions were automatically controlled with a 12-hour lightdark cycle with lights off at 06.00 a.m. Food (Altromin Standard Diet 1324) and tap water were provided ad libitum. Clean cages and new bedding were provided twice weekly. The animal welfare committee, appointed by the Danish Ministry of Justice, granted ethical permission for the studies. All procedures were carried out in compliance with the EC Directive 86/609/EEC and with the Danish law regulating experiments on animals (permission 2007/561-1396, C-schedule 1).

\section{DEX Exposure}

From GD 14 to 21, 40 rats were given daily s.c. injections with DEX, between 10.45 and 11.45 a.m., of which half received $50 \mu \mathrm{g} /$ $\mathrm{kg}$ (DEXlow) and half $150 \mu \mathrm{g} / \mathrm{kg}$ (DEXhigh). The 20 control $(\mathrm{CON})$ animals were injected s.c. with vehicle solution.

\section{Pregnancy and Lactation Data}

Forty-seven of the time-mated dams were observed with litters. The pups were weighed on postnatal day (PND) 3, and weaned at day 21 .

\section{Postweaning Investigations}

At weaning, 1 female per litter was selected at random for each postnatal group (CON, CONfst, DEXlow, DEXlowfst, DEXhigh and DEXhighfst) and housed in nonsibling pairs of similar prenatal exposure and postnatal testing (table 1). The animals were housed under conditions as already described except for addition of aspen chewing bars (Brogaarden ${ }^{\circledR}$, Denmark). From weaning, experimenters were kept unaware as to which prenatal exposure group the animals belonged. This was also in force during scoring of the FST data. Investigations were performed during the night phase of the diurnal cycle (dark phase) in the FST (see below) and the daylight phase (light phase) in the ASR test (between 8 a.m. and 5 p.m.). Animals from the different groups were equally distributed across the test days. Total group size: $\mathrm{n}=32 \mathrm{CON}, \mathrm{n}=24$ DEXlow and $n=36$ DEXhigh. Half the animals from each group were tested in the FST at 3 months of age.

Forced Swim Test

At 3 months, the animals from CONfst, DEXlowfst and DEXhighfst were tested in the FST as described previously [Porsolt,
1979; Porsolt et al., 1978] with minor modifications. Briefly, each rat was tested twice, $24 \mathrm{~h}$ apart. The animal was placed in a transparent cylindrical tank made from acrylic plastic (H: $55 \mathrm{~cm}, \mathrm{D}: 24$ $\mathrm{cm})$. Each tank contained $38 \mathrm{~cm}$ of tap water $\left(25^{\circ} \mathrm{C}\right)$ which was changed between each trial. On day 1 (training phase), each rat was in the tank for $15 \mathrm{~min}$, on day 2 (test phase) for $5 \mathrm{~min}$. The animals were taken directly from the colony room before being tested by transfer of the home cage to an adjacent laboratory. After each session, the animals were dried in a towel and placed in an animal container heated by a thermal lamp until dry. On both days, swim sessions were recorded on video. Scoring consisted of determining the dominant behavior within 5 -second intervals during the first $5 \mathrm{~min}$ of exposure time in each session. Behavior of the rats was divided into struggle, swim and immobility activity patterns according to Cryan et al. [2002].

The animals were not tested in the open field test prior to FST, as no difference in locomotion between prenatally DEX-exposed and CON animals was found in a pilot study in our laboratory.

\section{Open Field Pilot Study}

In a separate pilot study, female Sprague-Dawley offspring prenatally exposed to injections with $150 \mu \mathrm{g}$ DEX/kg (DEX) daily from GD 14 to 21, according to the protocol described in the main experiment, were tested for locomotion in a square open field at the age of 4 months.

Twelve DEX and $12 \mathrm{CON}$ were tested. The animals were observed for $5 \mathrm{~min}$ in a square open field $(100 \times 100 \mathrm{~cm})$ situated on the floor in a bright room. The rat was placed in the center of the field, and the movements of the rat were recorded by video camera and analyzed for ambulation by Noldus Ethovision ${ }^{\circledR}$ XT, version 5 . Between trials, the maze was cleaned with water.

\section{ASR and Prepulse Inhibition (PPI)}

All the animals were tested for ASR at the age of 6 months (table 1) using SR-Lab ${ }^{\text {TM }}$ SDI startle response system (SanDiego Instruments, Inc., Europe). Testing was conducted as previously described [Hougaard et al., 2005a; Kjaer et al., 2010].

At least $1 \mathrm{~h}$ before the test, the animals were transferred to the experimental room. Throughout the startle protocol, white background noise $[70 \mathrm{~dB}(\mathrm{~A})]$ was delivered continuously inside the chambers from a 3.5-inch tweeter (model BT2, MG Electronics, N.Y., USA) $14 \mathrm{~cm}$ above the animal holder (a Plexiglas tube $8.8 \mathrm{~cm}$ in diameter). The internal chamber light was on during testing. A 5 -min acclimatization period commenced test sessions that lasted approximately $20 \mathrm{~min}$ and consisted of 45 trials. The startle-eliciting stimulus consisted of a $40-\mathrm{ms}$ broadband $120 \mathrm{~dB}(\mathrm{~A})$ noise burst. Each session started and ended with 5 120-dB(A) startle trials followed by 35 test trials delivered in semirandomized order: 10 startle trials of $120 \mathrm{~dB}(\mathrm{~A}) ; 5$ each of 4 prepulses [72, 74, 78 and $86 \mathrm{~dB}(\mathrm{~A})$, respectively + startle trials denoted PPI72, PPI74, PPI78, and PPI86, respectively]; 5 trials with no stimulus except background noise. Movement of the tube was registered for 100 $\mathrm{ms}$ after onset of the startle stimulus (sampling frequency $1 \mathrm{kHz}$ ), amplified, and the average response over $100 \mathrm{~ms}$ (AVG) was calculated. For each level of prepulse, AVGs were averaged and used for calculation of PPI. PPI was expressed as percent reduction in AVG compared to the average of the 10 middle startle trials: $\% \mathrm{PPI}=100-[(\mathrm{AVG}$ at prepulse + startle trial $) /(\mathrm{AVG}$ at startle trial) $\times 100 \%]$. 
Statistics

Analysis of variance (ANOVA) was used to analyze pregnancy and lactation data (table 2). In order to avoid litter effects, the litter was considered the statistical unit. The average body weight of pups within a litter was therefore used for statistical analysis and only one pup per litter was included in each of the experimental groups. Analysis of covariance (ANCOVA) was used to test for differences in maternal body weight gain and pup weight while controlling for litter size. Kruskal-Wallis One-Way ANOVA was used to test for litter size and gestational length. Post hoc comparisons were performed by ANCOVA. Forced swim data were analyzed by two-way ANOVA. Day 1 and day 2 were analyzed separately for average immobility or struggling within the first 5 min each day with group (CONfst, DEXlowfst and DEXhighfst) as factor.

Startle data were analyzed by two-way ANOVA, with prenatal exposure (CON, DEXlow or DEXhigh) and postnatal background (naive or FST) as factors. For PPI, data were analyzed separately for each prepulse intensity. When appropriate, Fisher's LSD was applied for pairwise comparisons. The accepted level of statistical significance was $<0.05$ (SYSTAT Software Package version 12).

\section{Results}

\section{Pregnancy and Lactation Data}

Dams from the three groups were observed during pregnancy and lactation, and gestational data were recorded (table 2). No difference was found in litter size or gestational length between groups. Fewer DEXlow and CON dams gave birth to pups than DEXhigh. Of these pupless dams, 8 DEXlow and 3 CON showed no implantations, suggesting that impregnation had been unsuccessful. Maternal weight gain between GD 4 and 20 differed statistically significantly $[\mathrm{F}(2,43)=58.296 ; \mathrm{p}<$ 0.001] with litter size as covariate. Pairwise comparisons showed that CON dams gained more weight than both DEXlow ( $<<0.001)$ and DEXhigh $(p<0.001)$, and DEXlow dams gained more weight than DEXhigh $(\mathrm{p}=0.006)$. Offspring body weight at PND 3 (controlled for litter size) differed between groups $[\mathrm{F}(2,43)=29.507$; $\mathrm{p}<0.001]$. Pairwise comparisons indicated a differentiation between all groups with increasing DEX exposure level inversely associated with pup weight $(\mathrm{p}<0.05)$ for all comparisons. At PND 20, an overall difference in body weight was still discernible $[\mathrm{F}(2,42)=6.080 ; \mathrm{p}=0.005]$, due to lower weight of DEXhigh pups than CON ( $\mathrm{p}=0.001)$.

\section{Forced Swim Test}

CONfst, DEXlowfst and DEXhighfst were tested in the FST at the age of 3 months. Behavioral activity was measured for the first $5 \mathrm{~min}$ each day. ANOVA of day 1 showed statistically significant scored differences in
Table 2. Pregnancy and lactation data

\begin{tabular}{|c|c|c|c|}
\hline Endpoints & $\mathrm{CON}$ & DEXlow & DEXhigh \\
\hline Number of litters ${ }^{1}$ & 16 & 12 & 19 \\
\hline \multicolumn{4}{|l|}{ Maternal weight gain } \\
\hline GD $4-20, \mathrm{~g}^{2}$ & $98.4 \pm 2.4^{\mathrm{a}}$ & $64.5 \pm 3.7^{b}$ & $51.7 \pm 3.1^{\mathrm{c}}$ \\
\hline Gestation length, days & $22.9 \pm 0.1$ & $23 \pm 0.0$ & $23 \pm 0.1$ \\
\hline Implantations & $12.9 \pm 0.8$ & $12.8 \pm 0.6$ & $12.9 \pm 0.5$ \\
\hline Perinatal loss ${ }^{3}, \%$ & $13.2 \pm 5.9$ & $17.0 \pm 7.1$ & $26.0 \pm 5.9$ \\
\hline Live pups per litter & $11.8 \pm 0.9$ & $10.8 \pm 1.1$ & $9.6 \pm 0.8$ \\
\hline Female pups & $6.5 \pm 0.5$ & $5.5 \pm 0.8$ & $4.7 \pm 0.5$ \\
\hline Pup weight (PND 3), g & $7.5 \pm 0.2^{\mathrm{a}}$ & $6.6 \pm 0.2^{\mathrm{b}}$ & $5.2 \pm 0.2^{\mathrm{c}}$ \\
\hline Pup weight (PND 20), g & $31.7 \pm 1.0^{\mathrm{a}}$ & $31.7 \pm 0.8^{\mathrm{a}, \mathrm{b}}$ & $30.4 \pm 0.9^{\mathrm{b}}$ \\
\hline
\end{tabular}

Values are mean \pm SEM. Offspring parameters recorded on PND 3, unless otherwise stated. Pairwise comparisons were performed for maternal weight gain and pup weight, and values in the same row not showing a common superscript $\left({ }^{a}, \mathrm{~b}, \mathrm{c}\right)$ are significantly different $(0.001 \leq \mathrm{p} \leq 0.05)$.

${ }^{1}$ Initial number of mated females in each group was 20 .

${ }^{2}$ Females with no live pups were excluded from this analysis.

${ }^{3}$ Percentage includes dams showing implantations but with no live pups at PND 7. Of the 13 dams with no pups, 11 showed no implantations (8 DEXlow, 3 CON), 1 DEXhigh had 10 implants and $1 \mathrm{CON}$ had 1 implant.

immobility and struggling between treatment groups $[\mathrm{F}(2,43=4.419 ; \mathrm{p}=0.018)$ and $\mathrm{F}(2,43=4.833 ; \mathrm{p}=0.013)$, respectively]. Pairwise comparisons regarding effect of prenatal background demonstrated significantly increased immobility in DEXhighfst rats compared with CONfst $(\mathrm{p}=0.021)$ and DEXlowfst $(\mathrm{p}=0.012)$ (fig. 1a), and significantly less struggling in DEXhighfst compared with DEXlowfst $(\mathrm{p}=0.003)$ (fig. 1c). The same behavioral activity was visible on day 2 , although not statistically significant (fig.1b, d).

\section{Open Field Pilot Study}

Female offspring prenatally exposed to injections with $150 \mu \mathrm{g} D E X / \mathrm{kg}$ were tested in the open field test at the age of 4 months. One-way ANOVA showed no difference in ambulation between prenatal treatment groups (DEX: $2,654 \mathrm{~cm} ; \mathrm{CON}: 2,500 \mathrm{~cm})[\mathrm{F}(1,22=0.354) ; \mathrm{p}=0.5]$.

\section{Acoustic Startle Response}

Basal Startle. At the age of 6 months, all rats were tested for ASR. Overall statistical analysis indicated no variation with prenatal exposure or postnatal FST. The average basal startle response during the middle 10 startle trials was similar in all groups (fig. 2). Comparable out- 


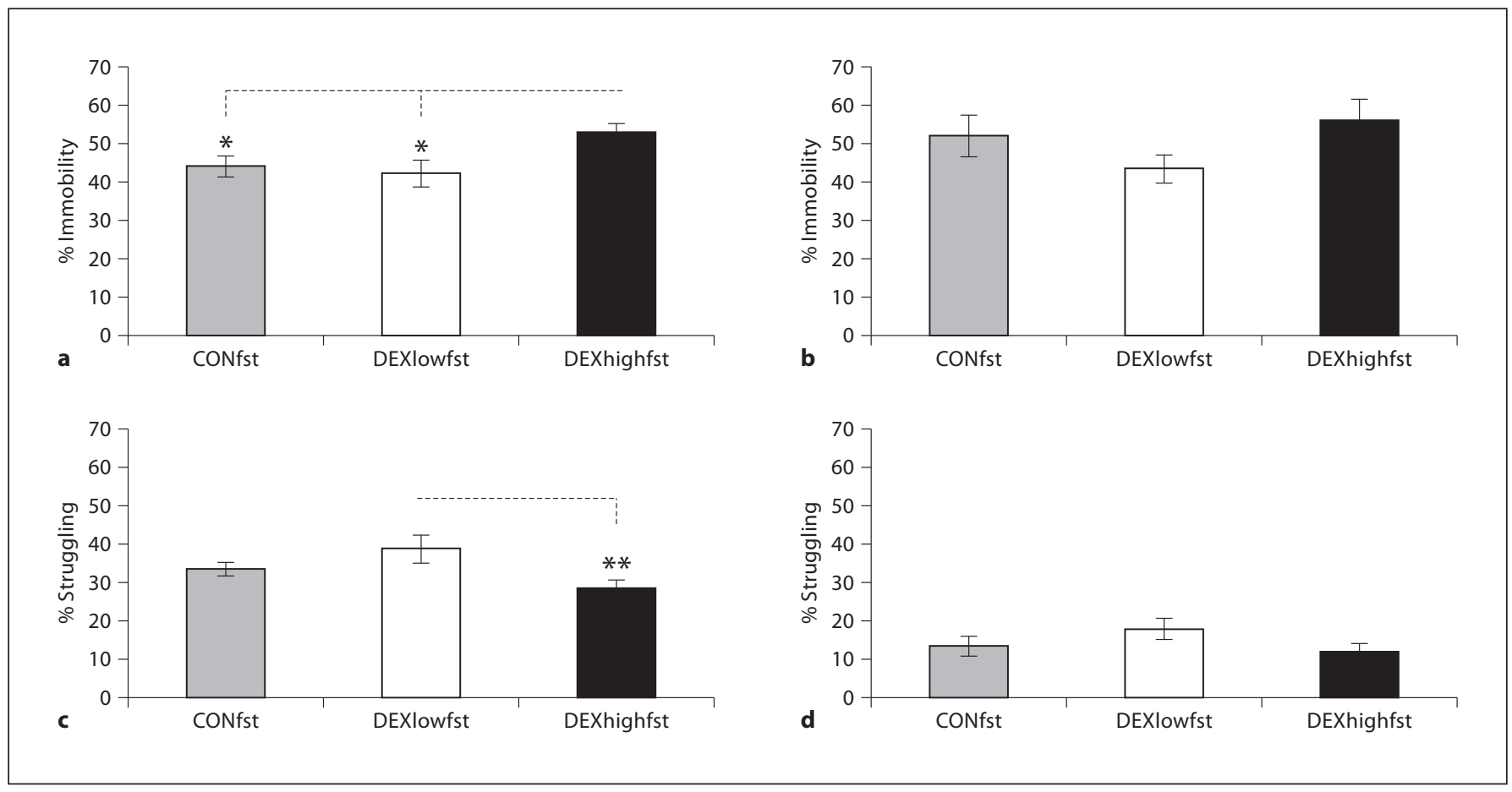

Fig. 1. FST in female rats, age 3 months. a Percent time spent immobile during initial 5 min (day 1$)$, group $[\mathrm{F}(2,43=4.419 ; \mathrm{p}=$ 0.018)]. b Percent time spent immobile during initial $5 \mathrm{~min}$ (day 2). c Percent time spent struggling during initial $5 \mathrm{~min}$ (day 1), group $[\mathrm{F}(2,43=4.833) ; \mathrm{p}=0.013]$. $\mathbf{d}$ Percent time spent struggling during initial 5 min (day 2). CONfst $=$ Control + FST; DEXlowfst $=$ prenatal DEX $50 \mu \mathrm{g} / \mathrm{kg}+$ FST; DEXhighfst = prenatal DEX $150 \mu \mathrm{g} / \mathrm{kg}+$ FST. $\mathrm{n}=16,12$, and 18 for CON, DEXlow and DEXhigh, respectively. Mean \pm SEM. ${ }^{*} \mathrm{p}<0.05,{ }^{* *} \mathrm{p}<0.01$.

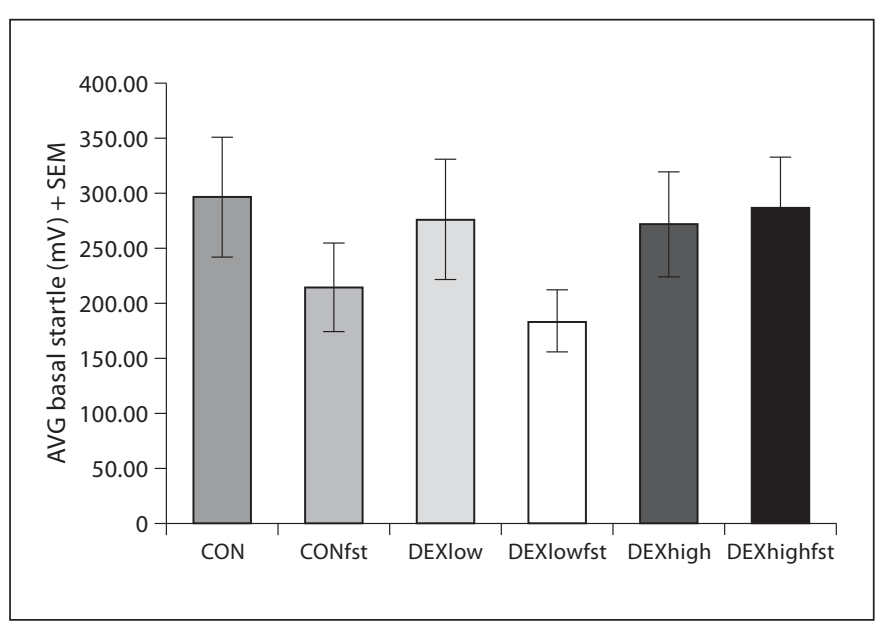

Fig. 2. Mean basal startle response to the middle ten 120 -dB startle trials in female rats. $\mathrm{CON}=$ Control; CONfst $=$ control + FST; DEXlow $=$ prenatal DEX $50 \mu \mathrm{g} / \mathrm{kg}$; DEXlowfst = prenatal DEX 50 $\mu \mathrm{g} / \mathrm{kg}+$ FST; DEXhigh $=$ prenatal DEX $150 \mu \mathrm{g} / \mathrm{kg} ;$ DEXhighfst $=$ prenatal DEX $150 \mu \mathrm{g} / \mathrm{kg}$ + FST. $\mathrm{n}=16,12$ and 18 for CON, DEXlow and DEXhigh, respectively. Mean \pm SEM. comes were registered for the 5 first and the 5 concluding startle trials [data not shown].

Prepulse Inhibition. PPI of the startle reaction to the $120-\mathrm{dB}$ noise pulse was investigated for four levels of prepulses $(72,74,78$, and $86 \mathrm{~dB})$. Statistical analysis showed that PPI72, PPI78 and PPI86 were similar in CON and DEX groups, but female offspring exposed to DEX in utero exhibited an increase of their mean average PPI74 independently of postnatal experience $[\mathrm{F}(2,86=6.189) ; \mathrm{p}=$ 0.003] (fig. 3).

\section{Discussion}

There are two main findings of the present paper. First, prior exposure to FST was unassociated with changes in basal startle. Second, we observed a differential effect of DEX on immobility and struggling on day 1 of the FST together with a clear dose effect of DEX on pup weight at PND 3, which was normalized for DEXlow but not DEXhigh at PND 20. 


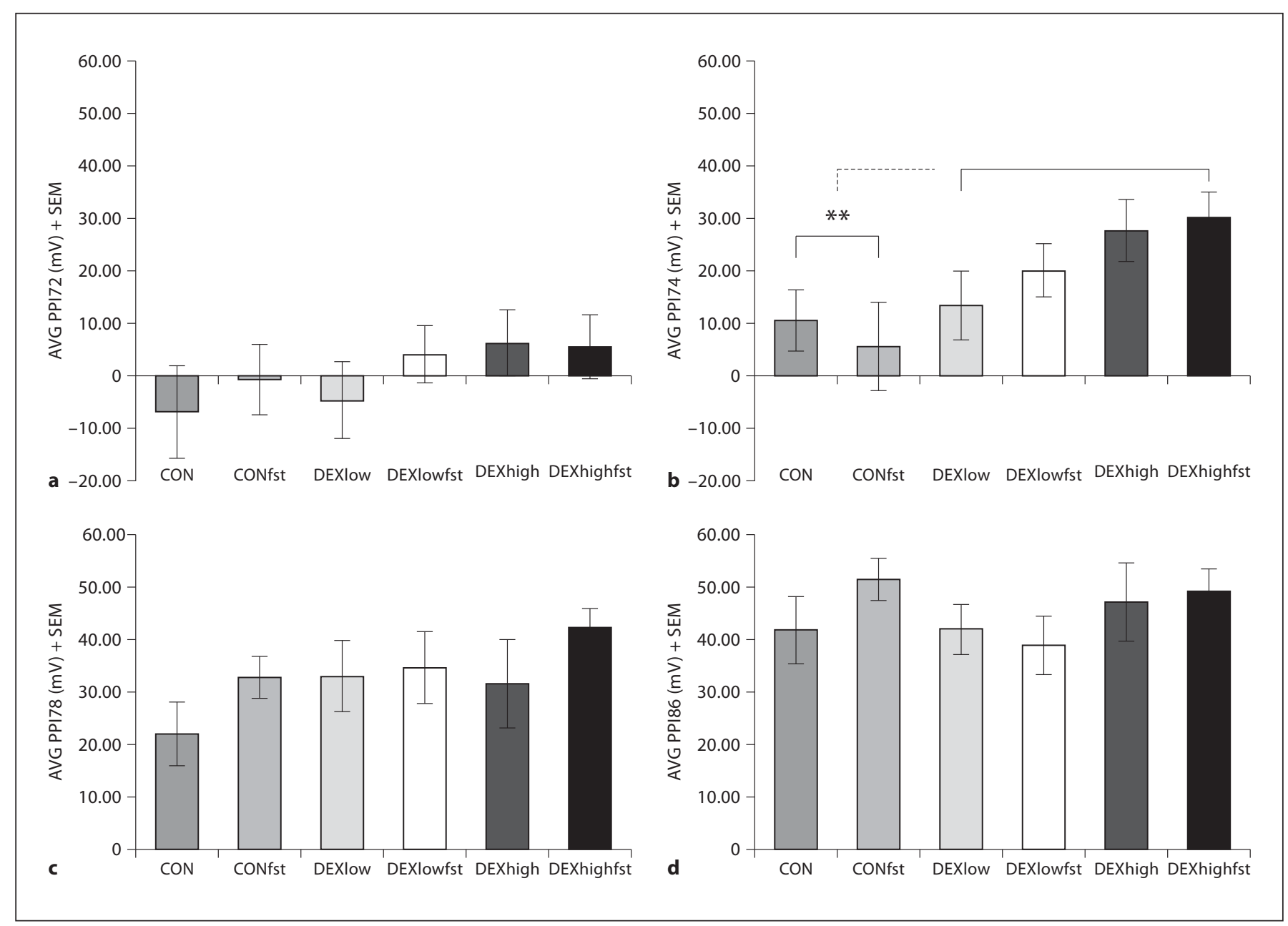

Fig. 3. Mean average PPI72 (a), PPI74 (b), PPI78 (c), and PPI86 (d) in female offspring at age 6 months. CON = Control; CONfst $=$ control + FST; DEXlow $=$ prenatal DEX $50 \mu \mathrm{g} / \mathrm{kg} ;$ DEXlowfst $=$ prenatal DEX $50 \mu \mathrm{g} / \mathrm{kg}+$ FST; DEXhigh = prenatal DEX $150 \mu \mathrm{g} / \mathrm{kg}$; DEXhighfst = prenatal DEX $150 \mu \mathrm{g} / \mathrm{kg}+\mathrm{FST} . \mathrm{n}=16,12$, and 18 for CON, DEXlow and DEXhigh, respectively. Mean \pm SEM. ${ }^{* *} \mathrm{p}<0.01$.

The combination of prenatal stress (chronic mild stress) or prenatal DEX $(100 \mu \mathrm{g} / \mathrm{kg})$ with postnatal stressful blood sampling has been associated with increased basal startle in two previous studies from our group [Hougaard et al., 2005a, b]. Since positive association between blood sampling and increased startle was not present in the CON group, this study hypothesized that the prenatal stress or DEX-exposed rats may conceive a contextual link (restraint) between the two experiences. In line with this, Fujioka et al. [2001] reported enhanced ability to remember an association between an aversive stimulus and contextual clues in prenatally stressed rats. Furthermore, since increased startle can be interpreted as increased levels of anxiety or fear, contextual awareness in prenatally stressed animals may correspond well with observation of anxious patients being sensitive to threatening contexts [Grillon, 2002]. In the present study, the combination of prenatal DEX exposure with FST was unassociated with changes in basal startle despite clear indications of affected behavior in DEXhigh rats in the FST. We suggest three different explanations for this: Firstly, the FST displayed no contextual similarities with the ASR test. Consequently, if the rats received no contextual warning of specific danger when placed in the ASR apparatus, this could explain the basal startle levels comparable with those of the CON animals. But since the blood sampling under restraint procedure was not included in this study, it remains speculative whether the contextu- 
ally more similar stressor would have elicited increased startle in the present experiment, as observed previously [Hougaard et al., 2005a, b]. Secondly, the FST may have exerted a different stress exposure than blood sampling under restraint used as postnatal stressor in previous studies [Hougaard et al., 2005a, b; Kjaer et al., 2010]. The FST has been compared with restraint stress among other stress forms [Bowers et al., 2008; Mercier et al., 2003]. These studies used duration of increased HPA axis activity in the form of plasma or serum corticosterone (CORT) levels and core temperature changes (among others) as measures for stress intensity. Mercier et al. [2003] observed neither increase in plasma CORT nor in colonic temperature after 20 -min swim stress, whereas $30-\mathrm{min}$ restraint resulted in increased colonic temperature, when assessed during the dark period. Bowers et al. [2008] reported similar increases in circulating CORT after one exposure to either stress form but higher CORT values in the restraint than the FST group after repeated exposures. Yet, the latter study used mice and a duration of forced swim of only 2 min whereas the restraint procedure lasted $2 \mathrm{~h}$ per session. Despite the differences observed, exposure to the FST is undoubtedly a powerful stressor, but it cannot be excluded that the physiological and psychological responses might vary between the two procedures which confront the animals with different challenges (restriction of movement, pain and smell of blood versus swimming without escape). Thirdly, the animals were exposed to different doses of DEX (150 or 50 $\mu \mathrm{g} / \mathrm{kg})$ than in our previous study $(100 \mu \mathrm{g}$ DEX/kg). It could therefore be speculated that the applied doses were less effective at eliciting increased basal startle than 100 $\mu g$ DEX/kg. Nevertheless, results from our lab have shown that a prenatal dose of $200 \mu \mathrm{g} D E X / \mathrm{kg}$ in combination with postnatal blood sampling under restraint was associated with highly increased basal startle [unpubl. data], which makes it less likely that dose difference alone suffices to explain the unaltered startle.

Female offspring exposed to DEX in utero exhibited an increase in PPI74 independently of postnatal experience. This pattern was not repeated for the other levels of prepulse, so the possibility of a chance finding is highly likely. In line with this, a study by Hauser et al. [2006] also observed increased PPI to a specific stimulus level (84 dB) in prenatal DEX males. Since this result could not be replicated in a second experiment run by the same group, it was classified as a weak finding [Hauser et al., 2006].

Immobility during forced swimming has been interpreted as development of passive behavior that disengages the animal from active forms of coping with stressful stimuli [Lucki, 1997]. In the present study, decreased mobility in the offspring from the DEXhigh group during their first exposure to the FST indicated a clear behavioral effect of the high prenatal DEX level, but the effect was only detectable on day 1 . In a study by Welberg et al. [2001], the dams received either DEX treatments $(100 \mu \mathrm{g} /$ $\mathrm{kg} /$ day) throughout pregnancy (DEX1-3) or during the last third of pregnancy (DEX3). Here, the adult offspring from both groups showed either no difference (DEX1-3) or increased mobility (DEX3) in the FST. A higher dose of DEX (1 mg/kg/day) but given only on GD 18 and 19 gave no effect on FST [Oliveira et al., 2006]. A very recent study performed by Hauser et al. [2009] has yielded highly interesting results. They exposed pregnant dams to 100 $\mu \mathrm{g} D E X / \mathrm{kg}$ per day during the last week of gestation through the drinking water, and offspring were crossfostered at birth to CON or DEX-exposed dams to enable separation of direct prenatal from indirect rearing dammediated effects of the treatment [Hauser et al., 2009]. The prenatal exposure was unassociated with changes in immobility, but rearing by a DEX-treated dam was associated with increased immobility in female rats [Hauser et al., 2009]. This importance of maternal care is supported by findings that maternal care/handling can affect the DNA methylation pattern [Weaver et al., 2004] and alter the stress responsiveness of the offspring [Meaney et al., 1988, 2007]. As decreased mobility was observed in DEXhigh and increased mobility was observed in DEXlow offspring, it would be interesting to study whether an association exists between DEX dose and maternal pup-directed behavior.

When considering changes in mobility as a behavioral response in the FST, the general locomotive drive of the animals should also be taken into account. Female rats exposed to $150 \mu \mathrm{g} \mathrm{DEX} / \mathrm{kg}$ showed no difference in locomotion in the open field when compared with CON animals in our pilot study. Similarly, Hauser et al. [2009] observed no effect of prenatal or rearing dam treatment (CON or DEX) on distance moved in the open field test. In the study by Welberg et al. [2001], adult offspring from DEX1-3 and DEX3 groups showed reduced exploratory behavior in an open field, yet no difference (DEX1-3) or increased mobility (DEX3) was observed in the FST. When the locomotive behavior as such appears unaffected by treatment, this could indicate that the mobility changes in the FST tests is a coping response more than an expression of locomotive drive of the animals. However, since our open field results were obtained in different animals than those tested in the FST, reduced locomotive drive cannot be ruled out as a possible explana- 
tion for the observation of reduced immobility in the DEXhigh group.

Welberg et al. [2001] observed increased mobility in (DEX3) animals. In line with this, our DEXlow offspring showed more struggling than the DEXhigh offspring. If increased mobility in the FST corresponds to increased coping and this increased mobility is facilitated by low levels of DEX, then it would be valuable to know what constitutes low glucocorticoid exposure: dose, timing or a combination. The dose of $50 \mu \mathrm{g} \mathrm{DEX} / \mathrm{kg}$ (GD 14-21) used in the present study might be too low for a clear effect of increased mobility as DEXlow offspring showed increased mobility compared with DEXhigh $(150 \mu \mathrm{g}$ $\mathrm{DEX} / \mathrm{kg}$ ), but comparable levels with CON. Similarly, Nagano et al. [2008] used $50 \mu \mathrm{g}$ DEX/kg during the 3rd week of gestation and observed no difference in mobility between CON and DEX-exposed male offspring. Timing of the stressor is also clearly important. Mobility was increased in animals treated with $100 \mu \mathrm{g}$ DEX/kg during the last week of gestation compared with CON animals, whereas animals exposed during the entire gestation showed no difference in mobility [Welberg et al., 2001]. The importance of interaction between dose and timing is in accordance with the concept of programming and neurodevelopment. Different cells and tissues are sensitive at different times, so the influences of environmental challenges will have distinct effects, depending not only on the challenge involved but also upon its timing [Seckl, 2004]. More studies are needed in this area to elucidate what might constitute a beneficial stress exposure. It should be noted, however, that coping ability was testspecific in our study, i.e. a difference between groups was observed in FST but not in basal startle, which makes it less clear-cut to distinguish between adaptive and maladaptive phenotypes.
Growth restriction in the offspring after glucocorticoid administration in the dam is a common finding [Newnham and Moss, 2001]. We observed a clear dose effect of DEX on pup weight at PND 3, normalized by PND 20 for DEXlow but not DEXhigh. This further supports the notion that the offspring were differentially affected by the different DEX concentrations.

In conclusion, we observed a differential effect of DEX on immobility and struggling in FST on day 1 but no effect on basal startle in the same animals. Possibly, contextual clues play a role for subsequent induction of increased basal startle reactivity in prenatally DEXexposed rats, but further studies are required to clearly determine which cues are relevant to observe an increase of basal startle response in animals exposed to DEX in utero. Also, different situations require different coping abilities in the same individual, and distinguishing between harmful and adaptive stressful exposures may not be apposite. Instead, the outcome of early-life experiences may be determined by the degree of 'match-mismatch' between prenatal exposures and future environment [Oitzl et al., 2009].

\section{Acknowledgments}

We thank Michael Guldbrandsen and Gitte Kristiansen for laboratory assistance and taking care of the animals. We also thank Simon Risum Sørensen for his impressive skills in constructing our FST tanks and Beate Finger for her instructions on how to manually score the FST. Our research was supported by the University of Aarhus, the National Research Centre for the Working Environment, the Lundbeck Foundation, the Dagmar Marshall Foundation, and the Eli Lilly Foundation.

\section{References}

- Abe H, Hidaka N, Kawagoe C, Odagiri K, Watanabe Y, Ikeda T, Ishizuka Y, Hashiguchi $\mathrm{H}$, Takeda R, Nishimori T, Ishida Y (2007): Prenatal psychological stress causes higher emotionality, depression-like behavior, and elevated activity in the hypothalamo-pituitary-adrenal axis. Neurosci Res 59:145-151.

- Anagnostaras SG, Josselyn SA, Frankland PW, Silva AJ (2000): Computer-assisted behavioral assessment of Pavlovian fear conditioning in mice. Learn Mem 7:58-72.
Bakker MJ, Tijssen MA, van der Meer JN, Koelman JH, Boer F (2009): Increased wholebody auditory startle reflex and autonomic reactivity in children with anxiety disorders. J Psychiatry Neurosci 34:314-322.

- Bowers SL, Bilbo SD, Dhabhar FS, Nelson RJ (2008): Stressor-specific alterations in corticosterone and immune responses in mice. Brain Behav Immun 22:105-113.

Cottrell EC, Seckl JR (2009): Prenatal stress, glucocorticoids and the programming of adult disease. Front Behav Neurosci 3:19.
Cryan JF, Markou A, Lucki I (2002): Assessing antidepressant activity in rodents: recent developments and future needs. Trends Pharmacol Sci 23:238-245.

$\checkmark$ DiPietro JA, Novak MF, Costigan KA, Atella LD, Reusing SP (2006): Maternal psychological distress during pregnancy in relation to child development at age two. Child Dev 77: 573-587.

Fujioka T, Fujioka A, Tan N, Chowdhury GM, Mouri H, Sakata Y, Nakamura S (2001): Mild prenatal stress enhances learning performance in the non-adopted rat offspring. Neuroscience 103:301-307. 
Fumagalli F, Molteni R, Racagni G, Riva MA (2007): Stress during development: impact on neuroplasticity and relevance to psychopathology. Prog Neurobiol 81:197-217.

Grillon C (2002): Startle reactivity and anxiety disorders: aversive conditioning, context, and neurobiology. Biol Psychiatry 52:958975.

Grillon C (2008): Models and mechanisms of anxiety: evidence from startle studies. Psychopharmacology (Berl) 199:421-437.

-Grillon C, Warner V, Hille J, Merikangas KR, Bruder GE, Tenke CE, Nomura Y, Leite P, Weissman MM (2005): Families at high and low risk for depression: a three-generation startle study. Biol Psychiatry 57:953-960.

-Harvey BH, Naciti C, Brand L, Stein DJ (2003): Endocrine, cognitive and hippocampal/cortical 5HT 1A/2A receptor changes evoked by a time-dependent sensitisation (TDS) stress model in rats. Brain Res 983:97-107.

Harvey BH, Naciti C, Brand L, Stein DJ (2004): Serotonin and stress: protective or malevolent actions in the biobehavioral response to repeated trauma? Ann NY Acad Sci 1032: 267-272.

-Hauser J, Feldon J, Pryce CR (2006): Prenatal dexamethasone exposure, postnatal development, and adulthood prepulse inhibition and latent inhibition in Wistar rats. Behav Brain Res 175:51-61.

Hauser J, Feldon J, Pryce CR (2009): Direct and dam-mediated effects of prenatal dexamethasone on emotionality, cognition and HPA axis in adult Wistar rats. Horm Behav 56: 364-375.

-Hossain A, Hajman K, Charitidi K, Erhardt S, Zimmermann U, Knipper M, Canlon B (2008): Prenatal dexamethasone impairs behavior and the activation of the BDNF exon IV promoter in the paraventricular nucleus in adult offspring. Endocrinology 149:63566365.

-Hougaard KS, Andersen MB, Hansen AM, Hass U, Werge T, Lund SP (2005a): Effects of prenatal exposure to chronic mild stress and toluene in rats. Neurotoxicol Teratol 27:153167.

-Hougaard KS, Andersen MB, Kjaer SL, Hansen AM, Werge T, Lund SP (2005b): Prenatal stress may increase vulnerability to life events: comparison with the effects of prenatal dexamethasone. Brain Res Dev Brain Res 159:55-63.
Kjaer SL, Wegener G, Rosenberg R, Lund SP, Hougaard KS (2010): Prenatal and adult stress interplay: behavioral implications. Brain Res 1320:106-113.

Koch M (1999): The neurobiology of startle. Prog Neurobiol 59:107-128.

Lucki I (1997): The forced swimming test as a model for core and component behavioral effects of antidepressant drugs. Behav Pharmacol 8:523-532.

-Maccari S, Darnaudery M, Morley-Fletcher S, Zuena AR, Cinque C, Van Reeth O (2003): Prenatal stress and long-term consequences: implications of glucocorticoid hormones. Neurosci Biobehav Rev 27:119-127.

-Maynard TM, Sikich L, Lieberman JA, LaMantia AS (2001): Neural development, cell-cell signaling, and the 'two-hit' hypothesis of schizophrenia. Schizophr Bull 27:457-476.

Meaney MJ, Aitken DH, van Berkel C, Bhatnagar S, Sapolsky RM (1988): Effect of neonatal handling on age-related impairments associated with the hippocampus. Science 239: 766-768

Meaney MJ, Szyf M, Seckl JR (2007): Epigenetic mechanisms of perinatal programming of hypothalamic-pituitary-adrenal function and health. Trends Mol Med 13:269-277.

-Mercier S, Canini F, Buguet A, Cespuglio R, Martin S, Bourdon L (2003): Behavioural changes after an acute stress: stressor and test types influences. Behav Brain Res 139: 167-175.

Nagano M, Ozawa H, Suzuki H (2008): Prenatal dexamethasone exposure affects anxietylike behaviour and neuroendocrine systems in an age-dependent manner. Neurosci Res 60:364-371.

Newnham JP, Moss TJ (2001): Antenatal glucocorticoids and growth: single versus multiple doses in animal and human studies. Semin Neonatol 6:285-292.

O'Connor TG, Heron J, Golding J, Beveridge M, Glover V (2002): Maternal antenatal anxiety and children's behavioural/emotional problems at 4 years. Report from the Avon Longitudinal Study of Parents and Children. Br J Psychiatry 180:502-508.

-Oitzl MS, Champagne DL, van der Veen R, De Kloet ER (2010): Brain development under stress: hypotheses of glucocorticoid actions revisited. Neurosci Biobehav Rev 34:853866.
Oliveira M, Bessa JM, Mesquita A, Tavares H, Carvalho A, Silva R, Pego JM, Cerqueira JJ, Palha JA, Almeida OF, Sousa N (2006): Induction of a hyperanxious state by antenatal dexamethasone: a case for less detrimental natural corticosteroids. Biol Psychiatry 59: 844-852.

Oosthuizen F, Wegener G, Harvey BH (2005): Nitric oxide as inflammatory mediator in post-traumatic stress disorder (PTSD): evidence from an animal model. Neuropsychiatr Dis Treat 1:109-123.

Porsolt RD (1979): Animal model of depression. Biomedicine 30:139-140.

Porsolt RD, Anton G, Blavet N, Jalfre M (1978): Behavioural despair in rats: a new model sensitive to antidepressant treatments. Eur J Pharmacol 47:379-391.

Seckl JR (2004): Prenatal glucocorticoids and long-term programming. Eur J Endocrinol 151(suppl 3):U49-U62.

Seckl JR, Meaney MJ (2004): Glucocorticoid programming. Ann NY Acad Sci 1032:63-84.

Tazumi T, Hori E, Uwano T, Umeno K, Tanebe K, Tabuchi E, Ono T, Nishijo H (2005): Effects of prenatal maternal stress by repeated cold environment on behavioral and emotional development in the rat offspring. Behav Brain Res 162:153-160.

-Van den Bergh BR, Mulder EJ, Mennes M, Glover V (2005): Antenatal maternal anxiety and stress and the neurobehavioural development of the fetus and child: links and possible mechanisms. A review. Neurosci Biobehav Rev 29:237-258.

-Van den Hove DL, Blanco CE, Aendekerk B, Desbonnet L, Bruschettini M, Steinbusch HP, Prickaerts J, Steinbusch HW (2005): Prenatal restraint stress and long-term affective consequences. Dev Neurosci 27:313-320.

Weaver IC (2009): Epigenetic effects of glucocorticoids. Semin Fetal Neonatal Med 14:143150 .

-Weaver IC, Cervoni N, Champagne FA, D'Alessio AC, Sharma S, Seckl JR, Dymov S, Szyf M, Meaney MJ (2004): Epigenetic programming by maternal behavior. Nat Neurosci 7:847854.

Welberg LA, Seckl JR, Holmes MC (2001): Prenatal glucocorticoid programming of brain corticosteroid receptors and corticotrophinreleasing hormone: possible implications for behaviour. Neuroscience 104:71-79.

World Health Organization (2008): The Global Burden of Disease: 2004 Update. 